ARTICLE

Mike G Phelps

Office for National Statistics

\title{
Comparing different estimates of productivity produced by the Office for National Statistics
}

\section{Introduction}

\section{SUMMARY}

This article describes the three different types of productivity measures which ONS publishes and examines the particular question of comparing public and private sector productivity. It shows that measures of output per person or person hour are not comparable with measures of output per unit of total input; and that measures of value-added per unit of input are not comparable with measures of gross output per unit of input. Approximate comparisons can be made of valued added productivity growth between the group of industries which include health, education and public administration and the market sector, though there is some overlap between the two.

D roductivity is broadly defined as output per unit of input and is an important indicator of the efficiency with which resources are being used. So it is natural for people to want to compare different areas of the economy to see how efficiency compares. There is particular interest in comparisons between the private sector and the public sector.

However, since both output and input can be defined in different ways, care needs to be taken that like is being compared with like. Output can be defined either as (inflation adjusted) value-added or (inflation adjusted) total output (gross output). On the input side, productivity measures sometimes look at only one input (usually persons or person-hours) and sometimes use a weighted average of all the relevant inputs that are used (including buildings and machines, for example). Measures using only labour as input are described as labour productivity, and measures that try to capture all inputs are called multi-factor productivity (MFP) measures.

Labour productivity will tend to increase faster than MFP if the amount of the nonlabour inputs per person is increasing. This is because extra machinery, for example, will tend to raise the amount of output a person produces. So comparing labour productivity measures with MFP measures is not appropriate: labour productivity can rise because of increases in labour quality or increase in the availability of capital inputs (for example, computers) or other non-labour inputs as well as pure efficiency gains.

Comparing value-added measures with total output measures is also inappropriate because value-added measures change more than the equivalent gross output measures.

This article describes the three different types of productivity measure that the Office for National Statistics (ONS) publishes and examines the particular question of comparing public and private sector productivity.

The three types of measure are:

- Value-added per person/person-hour for whole economy and industry group (labour productivity), published in a regular quarterly Statistical Bulletin

- Value-added per unit of total relevant input (a weighted average of qualityadjusted labour and capital (an MFP measure)), published as experimental statistics in Economic and Labour Market Review (ELMR)

- Gross output of publicly funded services per unit of total relevant input (a weighted average of quality adjusted labour, purchased inputs and capital (an MFP measure including purchased inputs)), published by government spending area (for example, health and education) and as an experimental total in a series of articles by the UK Centre for the Measurement of Government Activity (UKCeMGA)

ONS produces estimates of value-added per person and value-added MFP for 
the market sector, the subset of industry groupings that sell their output at economically meaningful prices. The market sector corresponds most closely with common understanding of what constitutes the private sector. Defining the public sector for the purposes of comparison is not quite so straightforward. There are a group of industries that cover most of public production, including health and education. But, strictly, these industries also include some market sector activity (for example, private education) as well as the output of the non-profit institutions serving households (NPISH) sector (including, for example, charities and higher education). Value-added labour productivity and MFP growth estimates are available for this set of industries too. So productivity growth can be compared between these two categories, provided the overlap in coverage is recognised.

Provision of publicly funded services, for which UKCeMGA produces MFP estimates, is a type of expenditure, not an industry group. Some of these services, for example hip replacements paid for by the NHS but performed by independent treatment centres, are provided by the market sector. These estimates are on a gross output not a value-added basis. They should not be compared with either value-added MFP or any labour productivity estimates.

The best approximation to a public/ private productivity comparison from published ONS figures is to compare the ELMR value-added MFP figures for the market sector, with value-added MFP figures for those industry groups that cover most public production and provision of public services.

\section{What is productivity?}

Productivity can be broadly defined as output per unit of input. This leads to several different definitions of productivity depending on three factors:

- how output is defined, in particular whether output is defined as valueadded (total value of sales minus the value of purchased goods and services used as intermediate inputs) or gross output (total value of sales)

- which inputs are used to construct the input figure used, in particular whether input is simply a measure of person or person-hours or whether it is instead a more complex weighted average of all inputs used, including, for example, the annual input from fixed equipment such as buildings and machines, and possibly differentiating between different kinds of labour input (so that an hour of specialist labour input is counted as greater input than a hour of unskilled labour input)

- which sector of the economy is being examined, in particular whether it is an industry grouping from the Standard Industrial Classification (SIC), for example manufacturing, whether it is a category of final spending, for example government provision of public services, or whether it is a sector defined by some other criterion such as the market sector, which consists of those activities that sell into a well-defined market. Some industries, for example education services, may be partly in the market sector and partly in the non-market sector and, similarly, some categories of spending, such as government provision of health services, may be partly provided directly through non-market production and partly by contracting out the provision of, for example, hip replacements to private sector contractors who form part of the market sector

Measures that use only persons or personhours as the input measure are usually referred to as labour productivity measures (output per person, or output per personhour). Measures that use a weighted average of many inputs as the input measure are usually referred to as multi-factor or total factor productivity.

\section{What does ONS publish?}

There are three types of productivity release produced by ONS; further details on each can be found in the ONS Productivity Handbook ${ }^{1}$.

The Statistical Bulletin on Productivity The Productivity Statistical Bulletin ${ }^{2}$ is published quarterly. The output measure used is value-added, derived from the relevant National Accounts release. The input measure used is labour, giving estimates of labour productivity (per worker, per job, per hour worked) for the whole economy. The figures come from the Labour Force Survey (LFS).

The productivity measures are broken down mainly by industry. Figures are available for whole economy; agriculture, forestry and fisheries; production industries; and services. Within production industries, manufacturing is separately identified and there is a further detailed breakdown within manufacturing. Within services, productivity figures are presented for distribution, hotels and catering; transport, storage and communication; and finance and business services. For the sectoral analysis, the labour input figures are based on reporting unit data derived from the workforce jobs series, but constrained so that the total equals the total from the LFS.

In addition to these industrial sector figures, experimental figures are also published for the market sector. The headline figure in the statistical bulletin is output per worker.

\section{Experimental estimates of multi- factor productivity}

Experimental estimates of multi-factor productivity (MFP) for the whole economy have been produced and published in Economic and Labour Market Review ${ }^{3}$.

The output measure used is valueadded, derived from the relevant National Accounts release. The inputs distinguished are quality adjusted labour input (QALI) and capital services, so it is a multi-factor productivity measure. Labour inputs in hours are quality adjusted using data drawn from the Labour Force Survey (LFS) on qualifications and experience (proxied by age and gender). The estimates of the quantity of labour input come from the same sources as those in the Productivity Statistical Bulletin. The quality adjustment is published in $\mathrm{ELMR}^{4}$. The measure of capital input is capital services and is also published in ELMR $^{5}$.

The estimates are broken down mainly by industry. Industrial disaggregation is limited by the sample sizes available in the LFS, which mean that accurate estimation of very disaggregated QALI is not possible. Estimates of MFP over the period 1998-2007 are given for the whole economy, and for various industry groupings. These include the group of industries classified as Sections $\mathrm{L}, \mathrm{M}, \mathrm{N}$, $\mathrm{O}, \mathrm{P}$ and $\mathrm{Q}$ (hereafter referred to simply as LMNOPQ): that is public administration and defence, education, health and social work, and other social and personal services. No MFP breakdown is currently available at any lower level for this group, though work is ongoing to develop a more detailed breakdown. The group is close in concept to the provision of public services, but it also includes private-sector-produced and NPISH-produced output which is sold directly to the personal sector, for example private education and healthcare.

As well as these industrial breakdowns, 
the article also provides MFP estimates for the market sector for the period 2001-2007. The market sector is broadly that part of the economy which sells its output at meaningful economic prices. It is defined as Sections A to J of the Standard Industrial Classification (SIC) plus Section K excluding the imputed rental for owner-occupiers, that part of Section $M$ (education) which is not provided by general government (note that this therefore includes universities and further education), Section $\mathrm{N}$ (health and social work) excluding that part provided by state health services and excluding social work and probation services carried out by government employees, and Section $\mathrm{O}$ (other community, social and personal service activities) excluding sewage and refuse disposal and environmental activities provided by local government and library and museum and recreation and tourism activities provided by local government. There is therefore some overlap between the market sector and the sector defined as LMNOPQ (note that the output of Q extra-territorial organisations - is zero for the UK).

Figure 1 shows average annual MFP growth for the whole economy, the market sector and LMNOPQ.

UKCeMGA estimates of total public service productivity

UKCeMGA was set up following a recommendation from the Atkinson Review. It has published a series of articles giving estimates of public service productivity $^{6}$, most recently estimates of total public service productivity for the period 1997-2007 (See Munro and Phelps 2009).

The output measure is a measure of the volume of the gross output (value-added plus intermediate inputs) of publicly funded public services (a component of GDP(E) (GDP expenditure approach), not GDP(O) (GDP output approach)). It is not a valueadded measure. (Because the estimates use gross output, the inputs measure includes intermediates as well as labour and capital.) And the gross output measure also includes quality adjustments that are not yet in National Accounts, which introduces further differences from the output measures used in the Productivity Statistical Bulletin and in the ELMR article.

The input measure used is a costweighted average of labour inputs, intermediate inputs of goods and services (included to match the output measure) and annual capital input. Labour is quality adjusted by differentiating different types of labour, for example, doctors and nurses, or teachers and teachers' assistants, not by using the standardised QALI approach described previously (which is not possible to reproduce at this level of disaggregation). The cost-weights are based on the total cost of each type of labour. The data comes from a variety of administrative sources; some of them direct measures of hours or quantities, others derived from expenditure data by applying appropriate deflators.

UKCeMGA measures, unlike any of the other measures so far discussed, are for a category of final spending, not an industrial sector. The estimates are broken down into various Classification of Functions of Government (COFOG) groupings, such as health or adult social care. These categories are close, but not identical, to the industrial categories covered in LMONPQ. However those categories also include output produced for the personal and NPISH sectors. And UKCeMGA measures can be broken down to a low level, whereas the value-added multi-factor productivity measure for LMNOPQ is only available for the group as a whole.
Figure 2 shows the percentage change in output, input and productivity since 1997 for total public services.

\section{What is the relationship between the different measures?}

The relationship between multi-factor productivity and labour productivity is straightforward. For example, using value-added as the output measure, the proportionate change in labour productivity, using value added per personhour, can be decomposed into several parts ${ }^{7}$. First is that part explained by changes in the quality of labour. If labour quality improves output would be expected to increase even if the number of hours of labour input were unchanged. Second is that part explained by changes in the amount of capital (fixed equipment such as computers, machine tools and so on) per person-hour. More capital per person will raise output without any increase in labour effort. Finally there is the remainder, which is multi-factor productivity growth. This picks up all the other factors including the efficiency of organisation (for example, better co-ordinated workflows and the

\section{Figure 1}

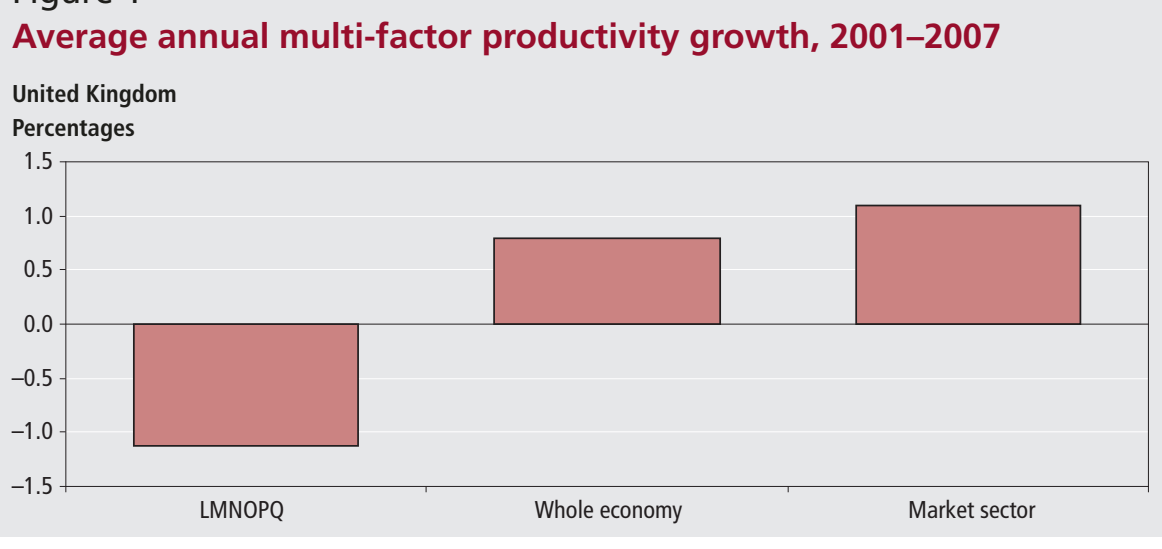

Source: Office for National Statistics

\section{Figure 2}

\section{Cumulative change in output, input and productivity in publicly funded services}

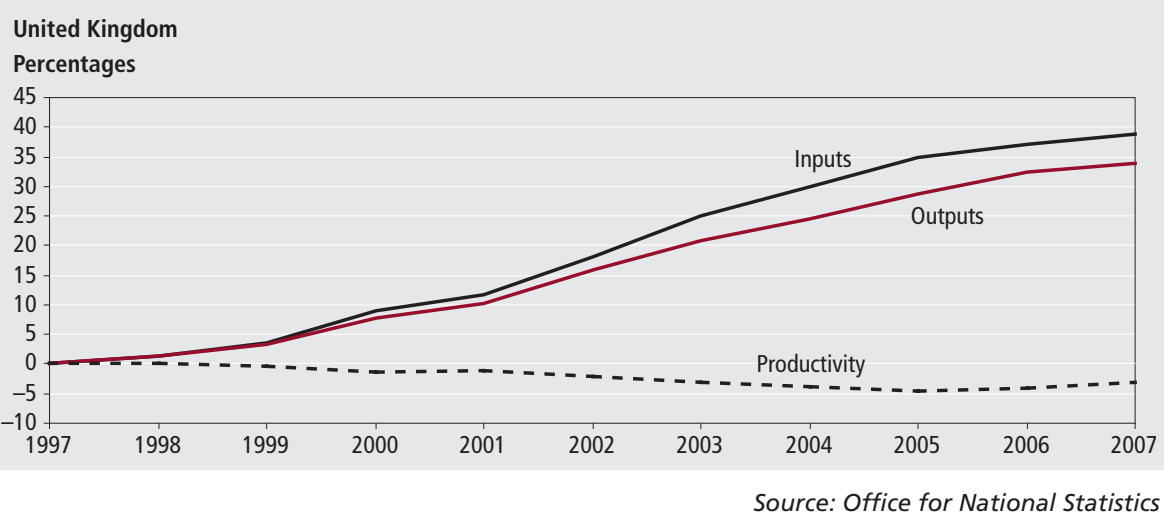




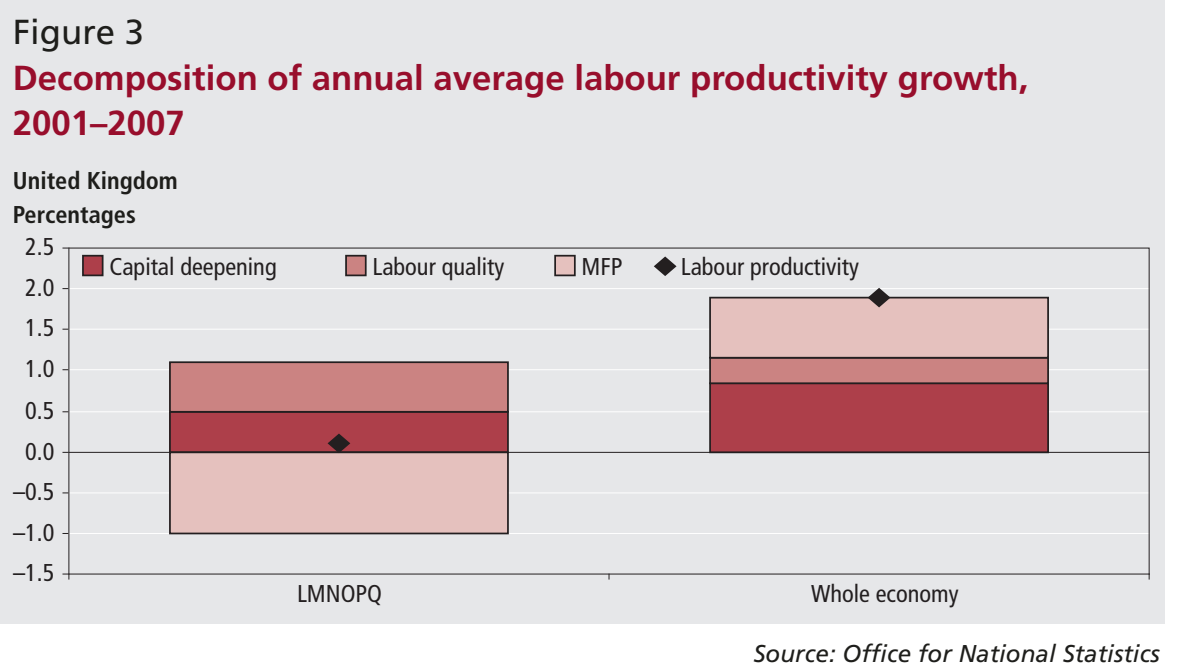

amount of labour effort). So, if labour quality is increasing and more capital equipment is being used per person-hour then labour productivity growth will exceed multi-factor productivity growth.

Similar relationships hold if gross output is used instead of value-added; but then we also have to include the contribution of intermediate inputs as an additional component.

There is also a simple relationship between gross output productivity and value-added productivity, derived by Bruno (1978) (see OECD (2001) Productivity Manual Chapter 3): the rate of change of value-added based multifactor productivity (MFP) equals the rate of change of gross output based MFP multiplied by the reciprocal of the nominal share of value-added in gross output (assuming both value-added and gross output refer to the same producing sector and assuming inputs are measured in the same way). The nominal share of valueadded in gross output (the ratio of valueadded to turnover) is less than one, so its reciprocal is greater than one. Therefore value-added productivity measures will move proportionately more than gross output productivity measures, and these differences will be magnified if the share of value-added in gross output decreases over time (as would happen if, for example, outsourcing rises over time).

\section{Can the different estimates be sensibly compared?}

Comparisons should be like with like. Comparing labour productivity measures for one sector with MFP estimates for another is potentially misleading. Some of the difference between the measures will reflect differences in the equipment used per person-hour and in labour quality rather than pure efficiency. Insofar those published by UKCeMGA, so the gap between public sector and market sector would be larger than simple comparisons would suggest. But if, instead, market sector estimates were adjusted to bring them onto a gross output basis, the market sector growth rates would be smaller and the gap between public service and market growth rates would be smaller than simple comparisons would suggest.

\section{Are gross output or value- added measures preferable?}

This raises the obvious question of which is the right comparison? It can be shown (see OECD (2001) Productivity Manual Chapter 3) that if technical progress affects all inputs proportionately (Hicks neutrality) then gross output productivity measures give estimates of underlying technical progress (assuming everyone is technically efficient to start with) and this is not true for the value-added measure. The value-added measure, because it depends on the share of value-added in gross output, depends not just on technology but also on the time paths of outputs, inputs and prices. It can be thought of as a measure of the ability of an industry to translate technical change into income and final demand. Value-added would precisely measure only technical change if technical change, instead of affecting all inputs equally, affected only primary inputs of capital and labour. However, this does not often seem to be the case. So the two measures are answers to different questions.

\section{Are there comparable estimates for the public and private sectors?}

There is much interest in comparing public sector performance and private sector performance. But it is important to be clear about what precisely constitutes the public and private sectors.

What most people mean by the private sector most closely corresponds to the market sector, which consists of those producers who sell their output at meaningful economic prices. ONS productivity estimates for this sector are based on value-added and are available for both labour productivity and MFP measures.

Defining the public sector is not straightforward. The public sector in National Accounts is defined as a set of institutions: central government, local government and public non-financial corporations. These institutions both provide output directly, for example local 
authority provision of education, and also arrange for buying services from the market sector or the NPISH sector (at economically meaningful prices) to be provided to persons (at zero or subsidised prices), for example hip operations provided to NHS patients by independent treatment centres.

A definition of the public sector comparable to the market sector would be the output of producers who do not sell at economically significant prices and are within the public sector. The closest approximation to this for which productivity estimates are published by ONS is the total of categories LMNOPQ of SIC (as defined earlier in the article). However, as already noted, this also includes some market sector activity (including activity of the not-for-profit institutions). Estimates for MFP for both of these 'sectors' were published in ELMR in March 2009 (see Munro and Phelps 2009). The estimates show that annual MFP growth in the market sector between 2001 and 2007 was 1.1 per cent, whereas for LMNOPQ it was approximately minus 1.0 per cent. Whole economy annual MFP growth over this period was 0.8 per cent.

UKCeMGA figures relate to the output bought by public funding and provided to, or on behalf of, people, regardless of who produces it. Some of the output is directly produced by the public sector as defined in the National Accounts, but some is produced by the market sector. The measure is a measure of final expenditure and is, therefore, a gross output measure. None of the other productivity figures ONS produces are on a gross output basis.

\section{Conclusion}

Existing ONS publications do not allow a straightforward comparison of productivity growth between public and private sectors. In particular, ONS does not publish a figure for the market sector that is directly comparable to the figure produced for MFP growth in the provision of gross output of public services.

The nearest approximation to a comparable public/private comparison using existing published figures would be to compare the growth of value-added in relation to the growth in inputs of capital and quality-adjusted labour for the market sector, as an approximation to the private sector, with that for the sum of industries LMNOPQ, which include most (but not all) of public service output as well as some market sector and NPISH sector output. ONS will investigate whether a better comparison of public and private sector productivity growth can be made available.

\section{Notes}

1 The Productivity Handbook, published in October 2008, brings together all ONS productivity measures and theories, and explains how they are sourced and formulated. This is available for download at: www.ons.gov.uk/about-statistics/userguidance/productivity-handbook/ index.htm

2 The latest version of the Productivity Statistical Bulletin is available at: www.statistics.gov.uk/StatBase/Product. asp? vlnk $=7476$

3 Turvey A (2009) 'Multi-factor productivity: estimates for 1998 to 2007, Economic and Labour Market Review vol. 3, no. 3, pp 33-38. Also available at:

www.statistics.gov.uk/cci/article. asp?ID=2147

4 Goodridge P (2009) 'Quality adjusted labour input: estimates for 1997 to 2007, Economic and Labour Market Review vol. 3, no. 1, pp 62-66. Also available at: www.statistics.gov.uk/cci/article. asp?ID $=2102$
5 Turvey A and Wallis G (2009) 'Volume of capital services: estimates for 1950 to 2007, Economic and Labour Market Review vol. 3, no. 1, pp 53-61. Also available at: www.statistics.gov.uk/cci/article. asp?ID=2105

6 For more information on UKCeMGA including a full set of publications visit the website at:

www.ons.gov.uk/about-statistics/ ukcemga/index.html

7 The exact relationship is that the proportionate change in labour productivity is equal to the proportionate change in labour quality per person-hour multiplied by the share of labour costs in total value-added plus the proportionate change in capital input per personhour times the share of capital in total valued added plus the proportionate change in multifactor productivity.

\section{CONTACT}

国elmr@ons.gov.uk

\section{REFERENCES}

Bruno M (1978), 'Duality, Intermediate Inputs and Value Added', in Fuss, Melvyn and Daniel McFadden (eds.), Production Economics: A Dual Approach to Theory and Applications

OECD (2001), Measuring Productivity OECD Manual, available at: www.oecd.org/dataoecd/59/29/2352458. pdf

Munro F and Phelps M (2009) 'Total Public Service Output and Productivity' June 2009, available at :

www.statistics.gov.uk/articles/nojournal/ TotalPublicServiceFinalv5.pdf 